\title{
Prevalence and course of thyroid dysfunction in neonates at high risk of Graves' disease or with non-autoimmune hyperthyroidism
}

\author{
Hassina Benlarbi', Dominique Simon ${ }^{1}$, Jonathan Rosenblatt ${ }^{2}$, Cecile Dumaine', Nicolas de Roux ${ }^{3,4}$, \\ Didier Chevenne ${ }^{4}$, Caroline Storey ${ }^{1}$, Amélie Poidvin ${ }^{1}$, Laetitia Martinerie ${ }^{1,3}$, Jean-Claude Carel ${ }^{1,3}$ and \\ Juliane Léger ${ }^{1,3}$
}

${ }^{1}$ Assistance Publique-Hôpitaux de Paris, Robert Debré University Hospital, Endocrinology-Diabetology Department, Reference Center for Growth and Development Endocrine Diseases, Paris, France, ${ }^{2}$ Assistance Publique-Hôpitaux de Paris, Robert Debré University Hospital, Obstetrics and Gynecology Department, Paris, France, ${ }^{3}$ Université de Paris, NeuroDiderot, Institut National de la Santé et de la Recherche Médicale (INSERM), Paris, France, and ${ }^{4}$ Assistance Publique-Hôpitaux de Paris, Biochemistry Unit, Robert Debré University Hospital, Paris, France

Correspondence should be addressed to J Léger

Email

juliane.leger@aphp.fr

\begin{abstract}
Objective: Neonatal hyperthyroidism may be caused by a permanent non-autoimmune genetic disorder or, more frequently, by maternally transmitted high serum TRAb levels. Variable thyroid dysfunction may be observed in this second context. We aimed to evaluate the prevalence of neonatal non-autoimmune hyperthyroidism and of the different types of thyroid function in neonates with a high risk of hyperthyroidism due to maternal Graves' disease (GD).

Design and methods: This observational cohort study included all neonates identified in the database of a single academic pediatric care center, over a period of 13 years, as having non-autoimmune hyperthyroidism or an autoimmune disorder with high TRAb levels (above $6 \mathrm{IU} / \mathrm{L}$ ) transmitted by their mothers. Patients were classified as having neonatal hyperthyroidism, hypothyroidism, or euthyroidism with a permanent or transient disorder. Results: Two of the 34 consecutive neonates selected (6\%) had permanent non-autoimmune hyperthyroidism due to germline $(n=1)$ or somatic $(n=1)$ mutations of the TSH receptor gene. The patients with high serum TRAb levels at birth had transient hyperthyroidism $(n=23$ ), hypothyroidism (primary $n=2$, central $n=3$ ) or persistent euthyroidism $(n=4)$.

Conclusion: These original findings highlight the need for careful and appropriate monitoring of thyroid function in the long term, not only for the rare patients with non-autoimmune neonatal hyperthyroidism, but also for repeat monitoring during the first month of life in neonates with maternally transmitted high TRAb levels, to ensure the early identification of thyrotoxicosis in more than two thirds of cases and to detect primary or central hypothyroidism, thereby potentially decreasing associated morbidity.
\end{abstract}

\section{Introduction}

Neonatal Graves' disease (GD) results from the passage of thyrotropin (TSH) receptor antibodies (TRAb) across the placenta, from the mother to the fetus. This condition is very rare, as only $1-2 \%$ of the babies born to mothers with a history of current or past GD have transient neonatal thyrotoxicosis. Its develops only in neonates with high levels of stimulatory TRAb activity, with a threshold more than 3.5 times the upper limit of the normal range of values https://eje.bioscientifica.com https://doi.org/10.1530/EJE-20-1320 (c) 2021 European Society of Endocrinology Printed in Great Britain
Published by Bioscientifica Ltd. 
at birth defining infants at risk of hyperthyroidism $(1,2,3$, $4,5,6,7,8,9)$. These neonates require careful management during the first few weeks of life, to ensure the clearance of these antibodies from the neonatal bloodstream. Mixtures of stimulating and blocking thyrotropin receptor antibodies may have different effects on neonatal thyroid function, resulting in transient hypothyroidism or transient hypothyroidism, followed by hyperthyroidism, or even euthyroidism, depending on the balance between the antibodies present, the relative proportions of which may change over time (10). The passage of excessive amounts of antithyroid drugs (ATD) across the placenta at the end of pregnancy may also induce transient hypothyroidism during the first $2-5$ days of life $(11,12)$. Finally, untreated or poorly controlled thyrotoxicosis in the mother may also affect the thyroid function of the offspring, resulting in central hypothyroidism (13, 14, $15,16)$. Clinical manifestations may be delayed or remain unrecognized, but timely diagnosis and treatment are important, given the risk of mortality and immediate and long-term morbidity $(17,18)$.

Non-autoimmune neonatal hyperthyroidism is rarer and may result from germline or somatic mutations of the thyroid-stimulating hormone receptor (TSH-R) gene, or from McCune-Albright syndrome. The hyperthyroidism observed in these cases is mostly permanent (19).

The aim of this study was to evaluate the prevalence of the clinical forms of thyroid dysfunction in neonates with high TRAb levels passing across the placenta from mothers with a history of GD, and in neonates with non-autoimmune hyperthyroidism, in a cohort of consecutive patients seen at a single academic pediatric care center.

\section{Patients and methods}

\section{Patients}

This observational cohort study included all patients identified, during the neonatal period, as having high levels of TRAbs ( $\geq 6 \mathrm{IU} / \mathrm{L})$ due to transplacental passage from a mother with a history of GD, or non-autoimmune hyperthyroidism, in the database of a single academic pediatric care center (the Pediatric Endocrinology Department of Robert Debré Hospital) between January 2006 and December 2018. The exclusion criterion was a TRAb level below $6 \mathrm{IU} / \mathrm{L}$ in infants born to mothers with gestational hyperthyroidism due to GD, or a past history of GD.

In total, 34 consecutive patients were identified and included in the study: 32 with high serum TRAb titers acquired from transplacental passage in a context of maternal GD, and two patients with non-autoimmune hyperthyroidism (Fig. 1).

\section{Study protocol}

The clinical data for each patient were obtained from the medical data recorded at each evaluation. The following

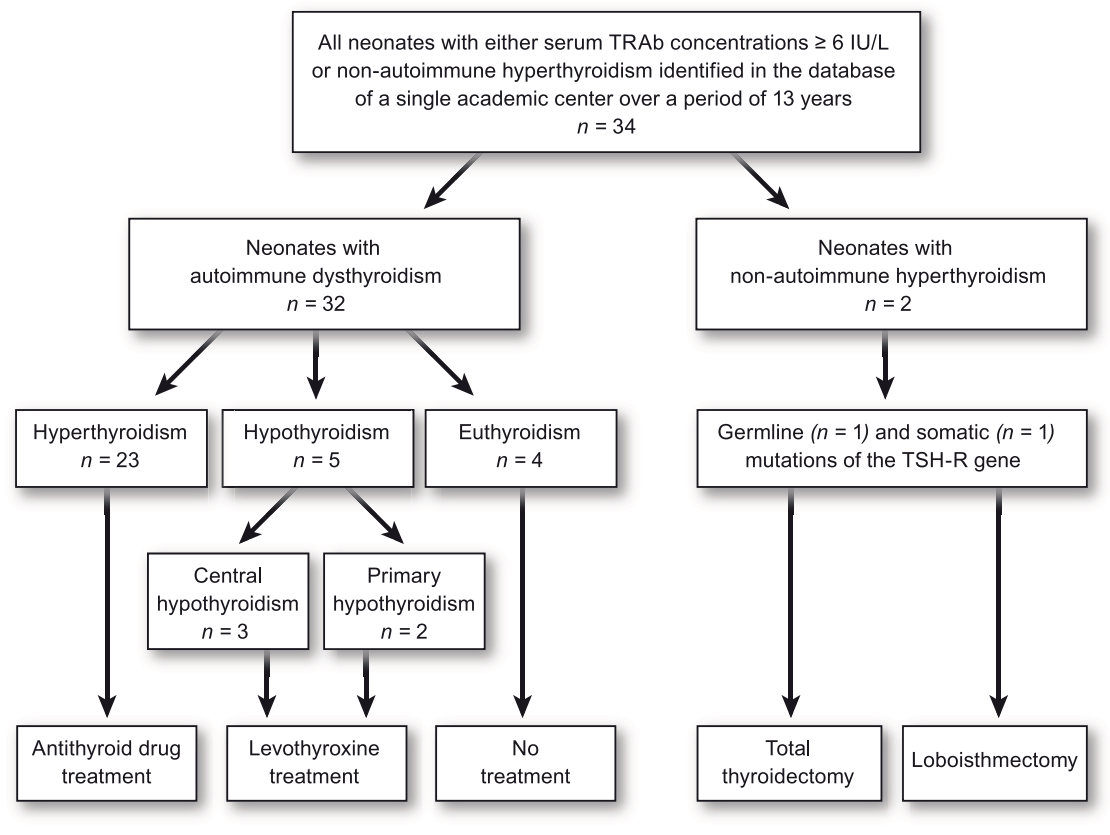

\section{Figure 1}

Distribution of the phenotypes of the 34 patients with non-autoimmune hyperthyroidism or autoimmune disorders with high TRAb levels transmitted from mothers with a history of GD. 
data were recorded at diagnosis: perinatal parameters and events, such as gestational age, birth weight, birth length, birth head circumference, mode of delivery, and neonatal distress, such as tachycardia ( $\geq 160$ beats/min); and neonatal history, including biochemical thyroid parameters and the results of thyroid ultrasonography. Maternal history of thyroid disease was assessed (when available) (Table 1). The maternal condition was identified as gestational GD with hyperthyroidism diagnosed before or during pregnancy, or any other known thyroid disorder.
Patients underwent a physical examination at birth and at subsequent visits (days 3, 5, 7, 10), and once every 1-2 weeks between the ages of 2 weeks and 3 months, with biochemical parameters (serum TSH, FT4, and TRAb levels) checked at each evaluation during the first 3 months, and serum TSH and FT4 levels checked two to three times per year thereafter, depending on the treatment used. The control of thyroid dysfunction was assessed by recording the management of anti-thyroid drugs (ATDs) and/or levothyroxine (L-T4) treatment during follow-up, its duration, clinical and laboratory test results, and outcome

Table 1 Characteristics of mothers who gave birth to infants with transient autoimmune hyperthyroidism (TAH), primary hypothyroidism (PHT), central hypothyroidism (CHT) and euthyroidism (ET).

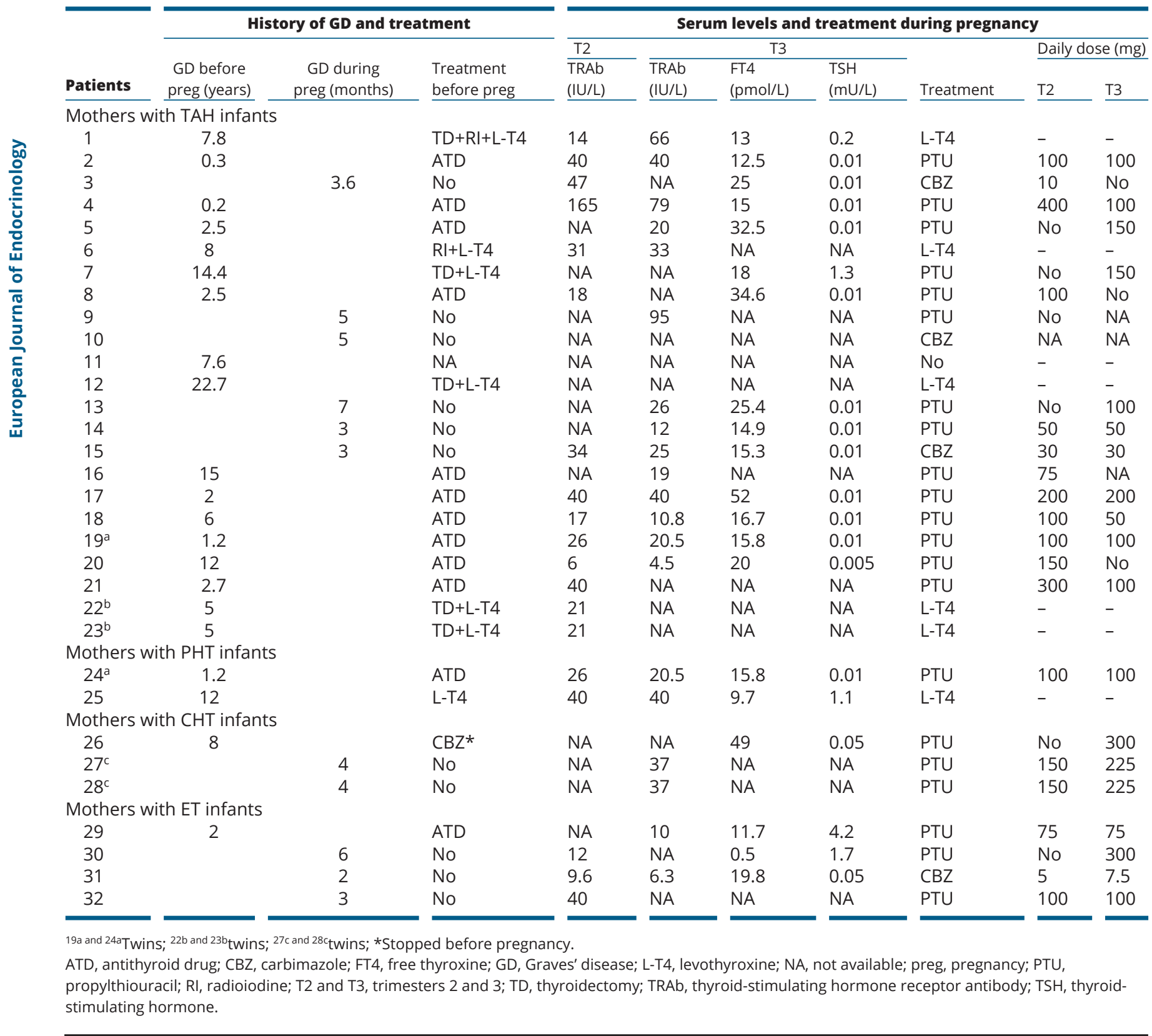


(Tables 2 and 3). Patients with hyperthyroidism were treated with carbimazole at a dose of $1 \mathrm{mg} / \mathrm{kg} /$ day, every 8 $\mathrm{h}$ until euthryroidism was achieved, and, thereafter, with either dose titration or block-and-replace treatment with a preparation of L-T4 in solution (one drop $=5 \mu \mathrm{g}$ ), until total elimination of the TRAbs from the patient's serum. The treatment was then stopped. All decisions concerning the management of ATD and/or L-T4 treatment were made on a case-by-case basis. Other treatments included total or partial thyroidectomy, in patients with non-autoimmune congenital hyperthyroidism.

A threshold TRAb concentration of $6 \mathrm{IU} / \mathrm{L}$, corresponding to 3.7 times the upper limit of the normal range was selected (above this threshold, careful monitoring was required to detect neonatal thyrotoxicosis), in accordance with current recommendations based on the high predictive value of neonatal hyperthyroidism, with a high sensitivity, but variable specificity, depending on the study $(4,6,7,8)$. Thyroid function during the neonatal period was classified into the following categories, according to the reference values for age (20): hyperthyroidism was defined as TSH undetectable in the serum, was considered overt if serum free thyroxine (FT4) levels were above the normal value for age ( $>35$ $\mathrm{pmol} / \mathrm{L}$ during the neonatal period) or as subclinical if serum FT4 levels were within the normal value for age; primary hypothyroidism was defined as high serum TSH concentration $(\geq 10 \mathrm{mIU} / \mathrm{L})$ and low serum FT4 concentration $(\leq 10 \mathrm{pmol} / \mathrm{L})$; central hypothyroidism was defined as normal serum TSH concentration and low serum FT4 concentration; euthyroidism was defined as normal thyroid function, as demonstrated by normal serum TSH and FT4 concentrations.

Non-autoimmune neonatal hyperthyroidism was considered in cases in which TRAb was undetectable in the serum at birth and/or during the first few days after birth.

Thyroid dysfunction was considered permanent or transient after the neonatal period, depending on whether serum TSH concentration and FT4 concentrations were normal (TSH between 0.5 and $6 \mathrm{mIU} / \mathrm{L}$, FT4 from 11 to $21 \mathrm{pmol} / \mathrm{L}$ ) for at least 4 weeks after the cessation of treatment.

The study protocol was approved by the Ethics Review Committee for Biomedical Research Projects of Robert Debré University Hospital, Assistance Publique Hôpitaux de Paris (CEERB No. 2016/290). Informed consent was obtained from the parents.

\section{Methods}

Patients were classified into five subgroups on the basis of their thyroid function from day 3 until the age of 4 months: neonatal transient or permanent hyperthyroidism, primary or central hypothyroidism and euthyroidism. Prematurity was defined as birth before a gestational age of 37 weeks. Birth weight, length and head circumference are expressed as percentiles for sex and gestational age, and small for gestational age (SGA) was defined as a birth length and/or weight $\leq 3$ rd percentile; microcephaly was defined as a head circumference $\leq 3^{\text {rd }}$ percentile. The size of the thyroid gland was estimated by clinical examination and by measurement on an ultrasound scan at diagnosis, and was classified as normal, or goiter (21).

Serum TSH and fT4 concentrations were determined by automated chemiluminescence immunoassays. Serum levels of thyrotropin receptor antibody, TRAb, were determined in second-generation human TRAb assays (human recombinant TSH receptor h-TBII assay; B.R.A.M.H.S., Clichy, France). Levels $>1$ IU/L were considered positive. The activities of serum thyrotropin receptor-stimulating antibodies (TSAb) and thyrotropin receptor-blocking antibodies (TBAb) were measured in bioassays (22), in two patients with primary hypothyroidism (these assays are time-consuming and expensive and were not, therefore, performed in all cases).

Molecular investigations of the TSH receptor gene were performed according to phenotype (on lymphocytes or thyroid tissues) for diagnosed cases of non-autoimmune hyperthyroidism.

\section{Statistical analysis}

The results are expressed as numerical values (percentages) for categorical variables, and medians (interquartile range) for continuous variables.

\section{Results}

The phenotypes of the 34 patients with and without neonatal autoimmune disorders are displayed in Fig. 1. Of the 32 patients with transplacental passage of TRAbs, 23 had neonatal hyperthyroidism, five had neonatal hypothyroidism (central $n=3$, primary $n=2$ ) and four patients remained euthyroid throughout follow-up, until the age of 3 months. The two patients with 
non-autoimmune hyperthyroidism had a germline and a somatic TSH-R mutation, respectively.

\section{Clinical characteristics, by thyroid phenotype}

- Neonatal autoimmune hyperthyroidism: The characteristics of the 23 neonates with transient autoimmune hyperthyroidism $(n=21)$ or subclinical hyperthyroidism $(n=2)$ are presented in Table 2 . Nine (39\%) were born premature, three $(13 \%)$ were small for gestational age and 14 (61\%) had a goiter. Median (interquartile range) patient age at treatment initiation was 7 (3-10) days, with median TSH and FT4 concentrations of $0.01(0.01-0.2) \mathrm{mIU} / \mathrm{L}$ and 49.6 (41.8-57.4) pmol/L, respectively. The initial dose of carbimazole was $1 \mathrm{mg} / \mathrm{kg} / \mathrm{day}$ and nine patients subsequently required levothyroxine treatment. The median titer of TRAbs was 24 (10-31) IU/L at diagnosis, just before treatment initiation, gradually decreasing thereafter, during the first 3 months of life. Serum FT4 levels mostly remained in the normal range during follow-up, although TSH remained undetectable in the serum for about 1 month. The median duration of ATD treatment was 53 (33-76) days, and TRAbs were undetectable in the serum at this time. Six of the 22 mothers of these infants (one woman gave birth to twins) were diagnosed with GD during pregnancy (two in the first trimester, three in the second trimester and one in the third trimester), and 16 had been diagnosed with GD before pregnancy and had been treated with radioiodine ( $n=1)$, by thyroidectomy $(n=3)$ or both $(n$ $=1$ ) before pregnancy or were still on ATD treatment $(n=10)$ before and during pregnancy. No information was available concerning the history of GD in one woman (patient no. 11).

- Neonatal hypothyroidism: The phenotypes of the five patients with primary $(n=2)$ and central $(n=3)$ hypothyroidism are shown in Table 3. Two patients with transient primary autoimmune hypothyroidism, with high serum TSH concentrations $(146 \mathrm{mIU} / \mathrm{L}$ and $80 \mathrm{mIU} / \mathrm{L}$ at the ages of 9 and 6 days, respectively) required rapid L-T4 treatment for 40 and 114 days, respectively. Serum TRAb titers were 13 and $>40 \mathrm{IU} / \mathrm{L}$, respectively, for these two patients. The mothers of these patients were treated for GD before pregnancy. One of these mothers was treated with $100 \mathrm{mg}$ propylthiouracil per day during the three trimesters of pregnancy, until delivery. Treatment with ATDs was stopped before pregnancy in the other mother. Her TBAb activity levels were very high, at $89 \%$, just after delivery, and her child also had high levels at delivery, which subsequently gradually decreased until the age of 120 days. Three neonates developed central hypothyroidism requiring L-T4 treatment for several months. They were born to mothers diagnosed with GD before $(n=1)$ or during ( $n=2$; twin pregnancy) pregnancy, with uncontrolled hyperthyroidism during the second half of gestation requiring an increase in ATD dose to 300 and $225 \mathrm{mg}$ per day, respectively, during the third trimester of pregnancy. Serum TRAb titers were elevated at birth, at 7.8, 18.5 and $19.5 \mathrm{IU} / \mathrm{L}$, respectively.

- Neonatal euthyroidism: Four patients were euthyroid and remained so throughout follow-up, until the age of 3 months. Serum TRAb titers were slightly high at birth in three of these patients, at 6.5, 8.8 and 10.9 IU/L, respectively. Serum TRAb titers were remarkably high, at $>40 \mathrm{IU} / \mathrm{L}$, in the fourth patient, but gradually decreased until the age of 3 months. Serum TRAb activities were measured by bioassays in this patient only. No TBAb was found in the evaluation performed at the age of 22 days; TSAb levels were very high, at $320 \%$, at this time point, although the patient remained euthyroid. However, the euthyroidism of these patients may reflect the presence of both stimulating and blocking activities.

- Neonatal non-autoimmune hyperthyroidism: The first patient was born premature, at a gestational age of 34 weeks, and a birth weight of $1850 \mathrm{~g}$. At the age of 5 days (and, retrospectively, also at birth), serum FT4 concentration was $100 \mathrm{pmol} / \mathrm{L}$, with TSH and TRAbs undetectable, the patients had a goiter (thyroid volume $1.7 \mathrm{~mL}$, with a volume of $1 \mathrm{~mL}$ considered normal for neonates born at term), and carbimazole treatment was introduced. The mother had a remarkable history, as she was diagnosed with hyperthyroidism at the age of 9 months and was subsequently treated with ATDs, undergoing thyroidectomy at the age of 9 years. The non-autoimmune hyperthyroidism of this patient was attributed to a heterozygous germline mutation leading to a Ser505Asp substitution in the transmembrane domain of the TSH-R, resulting in constitutive activation of the receptor. This germline TSH-R mutation was inherited from the mother, who was tested and found to have the mutation at the same time as her child. High doses of carbimazole (up to 2 $\mathrm{mg} / \mathrm{kg} / \mathrm{day}$ ) were required to control hyperthyroidism during follow-up, and a large goiter was observed. Total thyroidectomy was performed at the age of 2.8 years, and the patient required LT4 treatment thereafter. 
Table 2 Characteristics of the 23 neonates with transient autoimmune hyperthyroidism.

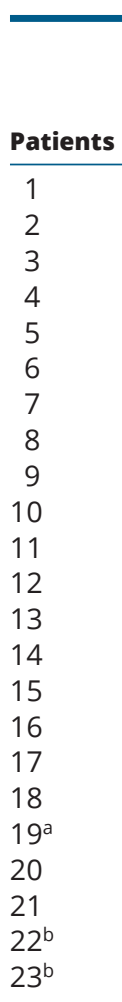

\begin{tabular}{|c|c|}
\hline Delivery & Premature \\
\hline IVD & No \\
\hline VD & No \\
\hline VD & No \\
\hline NA & No \\
\hline IVD & No \\
\hline VD & No \\
\hline VD & Yes \\
\hline VD & No \\
\hline VD & Yes \\
\hline VD & Yes \\
\hline NA & No \\
\hline CS & Yes \\
\hline IVD & No \\
\hline VD & No \\
\hline VD & No \\
\hline VD & No \\
\hline CS & Yes \\
\hline CS & No \\
\hline IVD & Yes \\
\hline VD & No \\
\hline VD & Yes \\
\hline CS & Yes \\
\hline CS & Yes \\
\hline
\end{tabular}

\begin{tabular}{l} 
data \\
SGA \\
No \\
Yes*** \\
No \\
No \\
No \\
No \\
No \\
No \\
No \\
Yes*** \\
No \\
No \\
No \\
No*** \\
No \\
No \\
Yes*** \\
No \\
NA \\
No \\
No \\
No \\
No \\
\hline
\end{tabular}

\begin{tabular}{|c|c|}
\hline $\begin{array}{l}\text { TRAb } \\
\text { (IU/L) }\end{array}$ & \begin{tabular}{l}
\multicolumn{1}{c|}{ At b } \\
TSH \\
$(\mathrm{mU} / \mathrm{L})$
\end{tabular} \\
\hline 66 & 0.01 \\
\hline 30.8 & NA \\
\hline 8 & 0.93 \\
\hline 40 & 1.31 \\
\hline 13.6 & 2.06 \\
\hline 33 & 0.22 \\
\hline$>40$ & 0.02 \\
\hline 40 & 3 \\
\hline 63 & 20 \\
\hline 8.1 & 0.06 \\
\hline$>40$ & 0.03 \\
\hline 40 & 0.01 \\
\hline 26 & NA \\
\hline 12 & 0.88 \\
\hline 19 & NA \\
\hline 11.3 & 8.8 \\
\hline 38.3 & 0.01 \\
\hline 11.6 & 2.65 \\
\hline 9.9 & 14.5 \\
\hline 7.4 & 3 \\
\hline 33.7 & 34.1 \\
\hline 9.5 & 0.01 \\
\hline 8.7 & 0.01 \\
\hline
\end{tabular}

\begin{tabular}{|c|c|}
\hline \multicolumn{2}{|c|}{ Serum levels } \\
\hline th & \\
\hline $\begin{array}{l}\text { FT4 } \\
\text { (pmol/L) }\end{array}$ & $\begin{array}{l}\text { TRAb } \\
\text { (IU/L) }\end{array}$ \\
\hline $19 * * * *$ & 24 \\
\hline NA & 20.3 \\
\hline 28.6 & NA \\
\hline 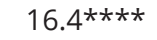 & NA \\
\hline 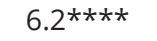 & NA \\
\hline $17.6 * \star * \star$ & 9.9 \\
\hline 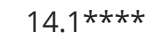 & 40 \\
\hline $16.4 * * * *$ & 27.6 \\
\hline 5.2 & 31.3 \\
\hline 38 & NA \\
\hline 64 & $>40$ \\
\hline 77 & NA \\
\hline NA & NA \\
\hline $14 * \star \star \star *$ & NA \\
\hline NA & 19 \\
\hline $23 * \star \star *$ & NA \\
\hline $41.5^{\star \star \star \star}$ & 38.3 \\
\hline $14.4 * * * *$ & NA \\
\hline 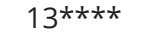 & 7.4 \\
\hline $17 * \star \star \star$ & 5.8 \\
\hline $9.9 * * * *$ & 23.8 \\
\hline 34.7 & 6.6 \\
\hline 26 & NA \\
\hline
\end{tabular}

\begin{tabular}{cc} 
& \\
\multicolumn{2}{c}{ At start of treatment } \\
TSH & FT4 \\
$(\mathrm{mU} / \mathrm{L})$ & $(\mathrm{pmol} / \mathrm{L})$
\end{tabular}

Treatment, + d

tTreatment was with carbimazole; **Association with L-T4; ***Microcephaly; **** Measurement performed on cord blood.

CS, Cesarean section; d, days; FT4, free thyroxine; IVD, instrumental vaginal delivery; L-T4, levothyroxine; NA, not available; SGA, small for gestational age; TRAb, thyroid-stimulating hormone receptor antibody; TSH, thyroid-stimulating hormone; VD, vaginal delivery; $22^{\mathrm{b}}$ and $23^{\mathrm{b}}$ twins, $19^{\mathrm{a}}$ and $24^{\mathrm{a}}$ twins,

$n=22^{\mathrm{b}}-23^{\mathrm{b}}$ subclinical hyperthyroidism. FT4 normal values: days $1-6: 11-35 \mathrm{pmol} / \mathrm{L}$, days $7-90: 12.7-30 \mathrm{pmol} / \mathrm{L}$

The second patient was born at term (birth weight 2940 g). Tachycardia was diagnosed from the third trimester of pregnancy, and the infant presented clinical signs of hyperthyroidism, with hyperexcitability, during the neonatal period, together with tachycardia (180 beats/ min). At diagnosis, serum FT4 concentration was very high, at $90 \mathrm{pmol} / \mathrm{L}$, and TSH and TRAbs were undetectable in the serum. Neither of the parents had thyroid disease. Ultrasonography and scintigraphy revealed the presence of a hyperfunctioning nodule $(23 \times 13 \mathrm{~mm})$ in the left thyroid lobe. A well-encapsulated autonomous adenoma was found during hemithyroidectomy performed at the age of 7 months. The patient then displayed hypothyroidism, requiring treatment with L-T4. A somatic gain-of-function mutation (C.1897 G>C; P.ASP 633 his) of the TSHR gene was found, in the heterozygous state, in the thyroid nodule, but not in the adjacent normal thyroid tissue.

\section{Discussion}

This observational cohort study is the first to analyze the prevalence of thyroid phenotypes in detail in both neonates with autoimmune disorders due to the passage of large amounts of TRAbs across the placenta from a mother with a history of GD and neonates with non-autoimmune hyperthyroidism. This study in well-characterized patients at a single center also provides extensive longitudinal data for various clinical presentations and outcomes in these patients. Unsurprisingly, the proportion of neonates with autoimmune disorders acquired from mothers with a history of GD was much higher than that of neonates with non-autoimmune hyperthyroidism. As expected, neonatal autoimmune hyperthyroidism was the most frequent underlying diagnosis in this cohort. However, we also found that about $28 \%$ of neonates acquiring high levels of TRAbs from mothers with a history of GD never had hyperthyroidism, instead presented with hypothyroidism or normal thyroid function in similar proportions.

In previous studies, high serum TRAb levels, more than 3.5 times the upper limit of the normal range, were identified as commonly associated with neonatal thyrotoxicosis, with sensitivity of $100 \%$ and a specificity of 53 to $94 \%(4,6)$. However, to our knowledge, no study 


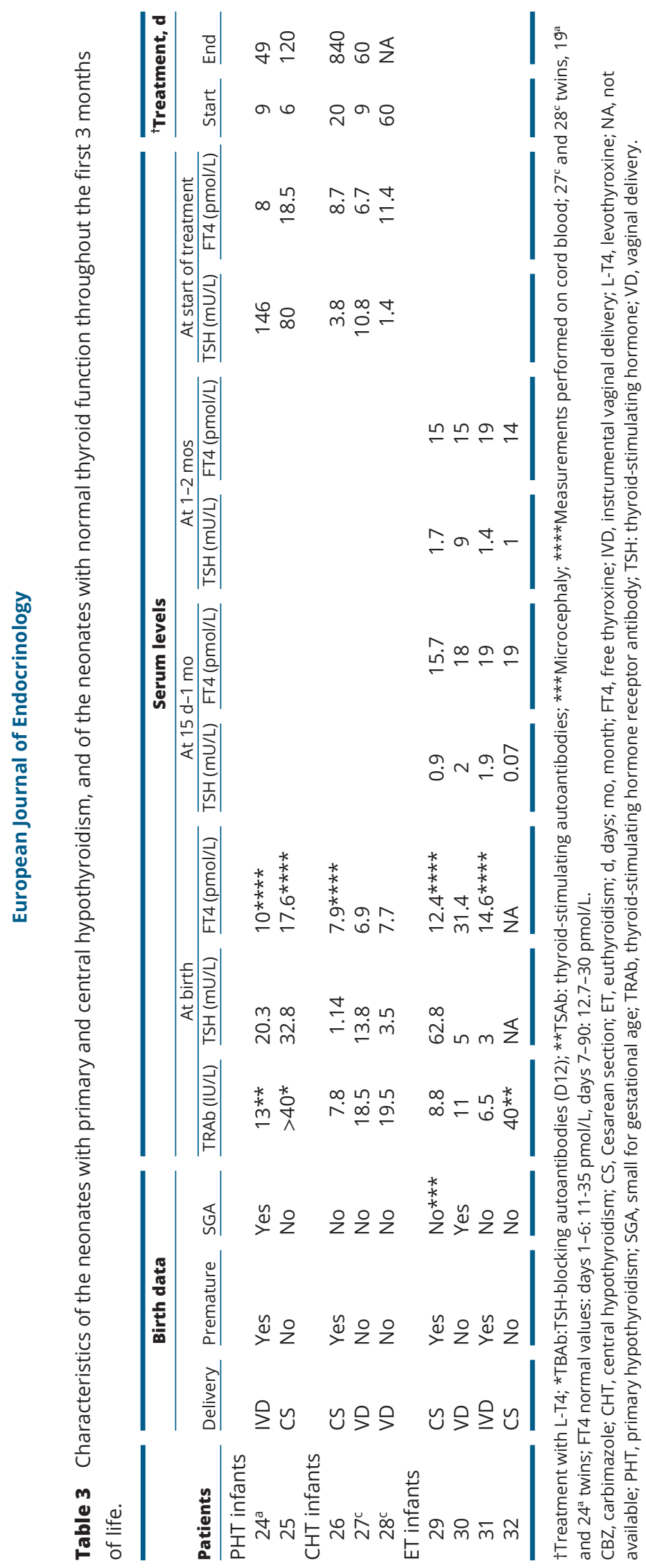

has ever presented comprehensive data on the prevalence of various types of thyroid function in a selected cohort of patients with high TRAb levels at birth. Previous cohort studies included mothers with a history of GD, with the aim of identifying predictors of neonatal hyperthyroidism. Various TRAb levels were demonstrated in these studies, from low to high, and epidemiological data concerning the clinical phenotypes of neonates without thyrotoxicosis and high TRAb levels are scarce (2, 3, 4, 5, 6, 23, 24, 25). Transient hypothyroidism due to a high daily dose of ATD was frequently hypothesized, but not truly demonstrated, and the infants presented hypothyroidism that persisted for the first 2 or 3 days of life, until the clearance of transplacentally transmitted ATDs from the mother (4, 5, $25)$, followed, in some cases, by thyrotoxicosis due to high TRAb levels. Transient congenital hypothyroidism due to the presence of TBAbs has also never been demonstrated in cohort studies, although one report considered its incidence by systematically screening blood spots from 788 neonates with suspected congenital hypothyroidism for TSH levels; It was concluded that about $2 \%$ of cases of congenital hypothyroidism were caused by maternal TBAbs (26). Moreover, central hypothyroidism was documented in only one previous cohort study (25), and most patients with central hypothyroidism were described in case reports or case series $(13,14,15,16,27)$, which provided no information about the prevalence of this disorder. TRAb levels in the third trimester, a high daily dose of ATD in mothers and very high serum FT4 levels during pregnancy have been shown to be significantly associated with neonatal thyroid dysfunction $(7,25)$. Our findings provide the first precise information about the respective prevalences of hyperthyroidism, hypothyroidism and normal thyroid function in neonates with high TRAb levels at birth due to passage across the placenta from mothers with a history of GD. Six of the 23 mothers were treated by thyroidectomy or with radioiodine before the pregnancy, but nevertheless had high serum TRAb levels. The serum TRAb levels of GD patients are known to increase after radioiodine (RAI) therapy, subsequently decreasing to pre-RAI therapy levels within a year. However, in some patients, such as the two mothers in our study, who received RAI 9 and 18 months, respectively, before pregnancy, these levels may remain high for years. This situation is less frequent after surgery (28). An incidence of neonatal hyperthyroidism of 5.5\% has been reported among the newborns of mothers who conceived within 2 years of radioiodine therapy (29).

In our study, the proportion of patients with hypothyroidism was higher than that reported in previous 
studies, in which hypothyroidism was limited to the first 2-3 days of life, mostly due to the use of high doses of ATDs in the mother by the end of the pregnancy $(4,5,6$, 25). TBAbs were likely to be present and responsible for hypothyroidism in our two patients, both of whom had overt hypothyroidism several days after birth, and for one of whom serum TBAb activity levels were already high at the end of the pregnancy.

The association of very high TRAb levels and normal thyroid function for several weeks after birth described here was not reported in any of the previous studies. The simultaneous presence of maternally transmitted and balanced levels of TSAb and TBAb, resulting in euthyroidism, is likely, although we were unable in this study to couple determinations of serum TRAb levels and biological activity. Neonatal hyperthyroidism may occur when TSAbs predominate, at any period after birth (with hypothyroidism occurring when TBAbs predominate), but the four patients of our cohort followed for several weeks, including the infant with very high TRAb levels during the first month of life, did not develop hyper- or hypothyroidism (10). These findings highlight the need for repeated measurements of serum TH levels during the first 4-6 weeks of life in neonates with high TRAb levels at birth displaying hypo or euthyroidism during the neonatal period.

Another important finding of our study is the association with central hypothyroidism, which is less frequently described in the newborns of mothers with GD, and is probably underdiagnosed. Previous case series or reports have described an association between uncontrolled hyperthyroidism during pregnancy and central hypothyroidism in the offspring $(13,14,15,16)$. The normal or slightly high serum TSH levels may be due to an overcorrection of TSH production by the pituitary gland in response to primary hypothyroidism. Impaired regulation of the fetal hypothalamic pituitary thyroid axis due to an increase in the transplacental passage of maternal thyroid hormones is likely in such cases, but the pathophysiological mechanism remains to be determined $(30,31,32)$. Repeated measurements of serum thyroid hormone levels should, therefore, be considered in all patients, particularly those born to mothers with uncontrolled severe hyperthyroidism during pregnancy.

Other types of neonatal hyperthyroidism associated with genetic disorders accounted for $6 \%$ of the cases in our cohort. Germline mutation of the TSH receptor gene, leading to its constitutive activation and hereditary autosomal dominant hyperthyroidism, was documented in one of our patients. Even with high doses of ATDs to control severe hyperthyroidism, goiter enlargement was observed early in life, necessitating thyroidectomy, as for other patients $(33,34,35)$. Autonomous adenomas secreting thyroid hormone due to somatic mutations of the TSH receptor gene are reported only exceptionally, and are much rarer in neonates than in adults $(36,37)$. Surgical excision of the nodule definitively cures the hyperthyroidism, but, in our patient, hemithyroidectomy caused hypothyroidism requiring long-term levothyroxine substitution treatment.

One of the major strengths of this study is the inclusion of all patients in a defined population for whom comprehensive data were prospectively collected at birth, at a single pediatric clinical center. This made it possible to evaluate all the demographic, clinical and biological characteristics of the patients during the neonatal period and, retrospectively, the history of thyroid disease in the mothers before and during pregnancy. We were, therefore, able to evaluate subgroups of individuals with different disorders during the neonatal period. The main limitation of this study is the observational nature of the retrospective data collection during follow-up, with treatment and monitoring stopped at various time points. It is also possible that neonates with TRAb levels $\geq 6 \mathrm{IU} / \mathrm{L}$ and only minor symptoms were not referred to our center and were not investigated as rigorously as recommended in clinical practice $(7,9,12)$, so the frequency of such events may have been underestimated. Despite the inclusion of all patients referred for TRAb levels $\geq 6 \mathrm{IU} / \mathrm{L}$ or for non-autoimmune hyperthyroidism, the sample size is small, and this study provides no new insight into the mechanisms underlying hypo- or euthyroidism in most patients, as serum TSAb and TBAb activities were not measured in all the patients displaying hypoor euthyroidism in our cohort, because this would have been too costly and time consuming. However, the comprehensive collection of data in this study made it possible to estimate the prevalence of each thyroid function disorder, and to make use of all observations in the estimation process.

In conclusion, the results of this observational study improve our understanding of the prevalence and course of the various clinical forms of thyroid function in neonates considered at high risk of developing thyrotoxicosis due to high serum TRAb levels transmitted from the mother, and in neonates with non-autoimmune hyperthyroidism. Our findings have important clinical implications for patient management, as they highlight the need for careful assessments of thyroid function, not only during the first few days of life, but repeatedly during the first 
month of life, in these vulnerable neonates with high serum TRAb levels transmitted from the mother. Such repeat determinations make it possible not only to identify cases of thyrotoxicosis early, but also to detect primary or central hypothyroidism, prompting early treatment, potentially attenuating the morbidity associated with these conditions. We also describe unexpectedly normal thyroid function in some cases.

Our observations reflect the complexity of thyroid function and dysfunction in neonates born to mothers with a history of GD. Less widely available thirdgeneration bioassays for determining the levels of thyroidstimulating or blocking immunoglobulins through the monitoring of cyclic AMP production may be used to predict subsequent thyroid function in some cases. Further studies are required to confirm these findings and to investigate clinical outcome and cognitive function in the long term, with a view to determining the impact of fetal and neonatal thyroid dysfunction in these patients during development.

\section{Declaration of interest}

J Léger is an editor of the journal (European Journal of Endocrinology). The other authors have no conflicts of interest relevant to this manuscript to disclose.

\section{Funding}

This research did not receive any specific grant from any funding agency in the public, commercial or not-for-profit sector.

\section{References}

1 Chopra IJ. Fetal and neonatal hyperthyroidism. Thyroid 19922 161-163. (https://doi.org/10.1089/thy.1992.2.161)

2 Clavel S, Madec AM, Bornet H, Deviller P, Stefanutti A \& Orgiazzi J. Anti TSH-receptor antibodies in pregnant patients with autoimmune thyroid disorder. British Journal of Obstetrics and Gynaecology 199097 1003-1008. (https://doi.org/10.1111/j.1471-0528.1990.tb02472.x)

3 Besancon A, Beltrand J, Le Gac I, Luton D \& Polak M. Management of neonates born to women with Graves' disease: a cohort study. European Journal of Endocrinology 2014170 855-862. (https://doi. org/10.1530/EJE-13-0994)

4 Abeillon-du Payrat J, Chikh K, Bossard N, Bretones P, Gaucherand P, Claris O, Charrié A, Raverot V, Orgiazzi J, Borson-Chazot F et al. Predictive value of maternal second-generation thyroid-binding inhibitory immunoglobulin assay for neonatal autoimmune hyperthyroidism. European Journal of Endocrinology 2014171 451-460. (https://doi.org/10.1530/EJE-14-0254)

5 Gietka-Czernel M, Debska M, Kretowicz P, Zgliczynski W \& Oltarzewski M. Hyperthyroidism during pregnancy - the role of measuring maternal TSH receptor antibodies and foetal ultrasound monitoring. Endokrynologia Polska 201465 259-268. (https://doi. org/10.5603/EP.2014.0035)

6 Banige M, Estellat C, Biran V, Desfrere L, Champion V, Benachi A, Ville Y, Dommergues M, Jarreau PH, Mokhtari M et al. Study of the factors leading to fetal and neonatal dysthyroidism in children of patients with Graves disease. Journal of the Endocrine Society $2017 \mathbf{1}$ 751-761. (https://doi.org/10.1210/js.2017-00189)

7 Alexander EK, Pearce EN, Brent GA, Brown RS, Chen H, Dosiou C, Grobman WA, Lauberg P, Lazarus JH, Mandel SJ et al. 2017 Guidelines of the American Thyroid Association for the diagnosis and management of thyroid disease during pregnancy and the postpartum. Thyroid 201727 315-389. (https://doi.org/10.1089/ thy.2016.0457)

8 van Dijk MM, Smits IH, Fliers E \& Bisschop PH. Maternal thyrotropin receptor antibody concentration and the risk of fetal and neonatal thyrotoxicosis: a systematic review. Thyroid $2018 \mathbf{2 8} 257-264$. (https://doi.org/10.1089/thy.2017.0413)

9 van der Kaay DC, Wasserman JD \& Palmert MR. Management of neonates born to mothers with Graves' disease. Pediatrics 2016137 e20151878. (https://doi.org/10.1542/peds.2015-1878)

10 McLachlan SM \& Rapoport B. Thyrotropin-blocking autoantibodies and thyroid-stimulating autoantibodies: potential mechanisms involved in the pendulum swinging from hypothyroidism to hyperthyroidism or vice versa. Thyroid 201323 14-24. (https://doi. org/10.1089/thy.2012.0374)

11 Cooper DS \& Laurberg P. Hyperthyroidism in pregnancy. Lancet: Diabetes and Endocrinology 20131 238-249. (https://doi.org/10.1016/ S2213-8587(13)70086-X)

12 Leger J. Management of fetal and neonatal Graves' disease. Hormone Research in Paediatrics 201787 1-6. (https://doi. org/10.1159/000453065)

13 Higuchi R, Kumagai T, Kobayashi M, Minami T, Koyama H \& Ishii Y. Short-term hyperthyroidism followed by transient pituitary hypothyroidism in a very low birth weight infant born to a mother with uncontrolled Graves' disease. Pediatrics 2001107 E57. (https:// doi.org/10.1542/peds.107.4.e57)

14 Lee YS, Loke KY, Ng SC \& Joseph R. Maternal thyrotoxicosis causing central hypothyroidism in infants. Journal of Paediatrics and Child Health 200238 206-208. (https://doi.org/10.1046/j.14401754.2002.00741.x)

15 Kempers MJ, van Tijn DA, van Trotsenburg AS, de Vijlder JJ, Wiedijk BM \& Vulsma T. Central congenital hypothyroidism due to gestational hyperthyroidism: detection where prevention failed. Journal of Clinical Endocrinology and Metabolism 200388 5851-5857. (https://doi.org/10.1210/jc.2003-030665)

16 Peeters D, van Gijlswijk S, Leunissen RW \& van der Kaay DCM. Central congenital hypothyroidism caused by maternal thyrotoxicosis. BMJ Case Reports 2018 2018. (https://doi. org/10.1136/bcr-2017-222620)

17 Zimmerman D \& Gan-Gaisano M. Hyperthyroidism in children and adolescents. Pediatric Clinics of North America 199037 1273-1295. (https://doi.org/10.1016/s0031-3955(16)37011-0)

18 Daneman D \& Howard NJ. Neonatal thyrotoxicosis: intellectual impairment and craniosynostosis in later years. Journal of Pediatrics 198097 257-259. (https://doi.org/10.1016/s00223476(80)80487-2)

19 Zimmerman D. Fetal and neonatal hyperthyroidism. Thyroid 19999 727-733. (https://doi.org/10.1089/thy.1999.9.727)

20 Kratzsch J, Schubert G, Pulzer F, Pfaeffle R, Koerner A, Dietz A, Rauh M, Kiess W \& Thiery J. Reference intervals for TSH and thyroid hormones are mainly affected by age, body mass index and number of blood leucocytes, but hardly by gender and thyroid autoantibodies during the first decades of life. Clinical Biochemistry $2008 \mathbf{4 1}$ 1091-1098. (https://doi.org/10.1016/j.clinbiochem.2008.04.007)

21 Mikolajczak A, Borszewska-Kornacka MK \& Bokiniec R. Sonographic reference ranges for the thyroid gland in euthyroid term newborns. American Journal of Perinatology 201532 1257-1262. (https://doi. org/10.1055/s-0035-1552937)

22 Madec AM, Clavel S, Stefanutti A \& Orgiazzi J. Blocking antithyrotropin receptor antibodies desensitize cultured human thyroid 
cells. Endocrinology 1988123 2062-2066. (https://doi.org/10.1210/ endo-123-4-2062)

23 Kamijo K. TSH-receptor antibodies determined by the first, second and third generation assays and thyroid-stimulating antibody in pregnant patients with Graves' disease. Endocrine Journal 200754 619-624. (https://doi.org/10.1507/endocrj.k06-196)

24 Elston MS, Tu'akoi K, Meyer-Rochow GY, Tamatea JA \& Conaglen JV. Pregnancy after definitive treatment for Graves' disease - does treatment choice influence outcome? Australian and New Zealand Journal of Obstetrics and Gynaecology 201454 317-321. (https://doi. org/10.1111/ajo.12196)

25 Uenaka M, Tanimura K, Tairaku S, Morioka I, Ebina Y \& Yamada H. Risk factors for neonatal thyroid dysfunction in pregnancies complicated by Graves' disease. European Journal of Obstetrics, Gynecology, and Reproductive Biology 2014177 89-93. (https://doi. org/10.1016/j.ejogrb.2014.03.007)

26 Brown RS, Bellisario RL, Botero D, Fournier L, Abrams CA, Cowger ML, David R, Fort P \& Richman RA. Incidence of transient congenital hypothyroidism due to maternal thyrotropin receptorblocking antibodies in over one million babies. Journal of Clinical Endocrinology and Metabolism 199681 1147-1151. (https://doi. org/10.1210/jcem.81.3.8772590)

27 Kempers MJ, van Trotsenburg AS, van Rijn RR, Smets AM, Smit BJ, de Vijlder JJ \& Vulsma T. Loss of integrity of thyroid morphology and function in children born to mothers with inadequately treated Graves' disease. Journal of Clinical Endocrinology and Metabolism 2007 92 2984-2991. (https://doi.org/10.1210/jc.2006-2042)

28 Laurberg P, Wallin G, Tallstedt L, Abraham-Nordling M, Lundell G \& Torring O. TSH-receptor autoimmunity in Graves' disease after therapy with anti-thyroid drugs, surgery, or radioiodine: a 5-year prospective randomized study. European Journal of Endocrinology 2008 158 69-75. (https://doi.org/10.1530/EJE-07-0450)

29 Yoshihara A, Iwaku K, Noh JY, Watanabe N, Kunii Y, Ohye H, Suzuki M, Matsumoto M, Suzuki N, Tadokoro R et al. Incidence of neonatal hyperthyroidism among newborns of Graves' disease patients treated with radioiodine therapy. Thyroid 201929 128-134. (https://doi.org/10.1089/thy.2018.0165)

30 Matsuura N, Harada S, Ohyama Y, Shibayama K, Fukushi M, Ishikawa N, Yuri K, Nakanishi M, Yokota Y, Kazahari K et al. The mechanisms of transient hypothyroxinemia in infants born to mothers with Graves' disease. Pediatric Research 1997 42 214-218. (https://doi.org/10.1203/00006450199708000-00014)

31 Prummel MF, Brokken LJ \& Wiersinga WM. Ultra short-loop feedback control of thyrotropin secretion. Thyroid 200414 825-829. (https:// doi.org/10.1089/thy.2004.14.825)

32 Zwaveling-Soonawala N, van Trotsenburg P \& Vulsma T. Central hypothyroidism in an infant born to an adequately treated mother with Graves' disease: an effect of maternally derived thyrotrophin receptor antibodies? Thyroid 200919 661-662. (https://doi. org/10.1089/thy.2008.0348)

33 Kopp P, van Sande J, Parma J, Duprez L, Gerber H, Joss E, Jameson JL, Dumont JE \& Vassart G. Brief report: congenital hyperthyroidism caused by a mutation in the thyrotropin-receptor gene. New England Journal of Medicine 1995332 150-154. (https://doi.org/10.1056/ NEJM199501193320304)

34 Schwab KO, Gerlich M, Broecker M, Sohlemann P, Derwahl M $\&$ Lohse MJ. Constitutively active germline mutation of the thyrotropin receptor gene as a cause of congenital hyperthyroidism. Journal of Pediatrics 1997131 899-904. (https://doi.org/10.1016/ s0022-3476(97)70040-4)

35 Gelwane G, de Roux N, Chevenne D, Carel JC \& Leger J. Pituitarythyroid feedback in a patient with a sporadic activating thyrotropin (TSH) receptor mutation: implication that thyroid-secreted factors other than thyroid hormones contribute to serum TSH levels. Journal of Clinical Endocrinology and Metabolism 200994 2787-2791. (https:// doi.org/10.1210/jc.2008-2524)

36 Kopp P, Muirhead S, Jourdain N, Gu WX, Jameson JL \& Rodd C. Congenital hyperthyroidism caused by a solitary toxic adenoma harboring a novel somatic mutation (serine281-->isoleucine) in the extracellular domain of the thyrotropin receptor. Journal of Clinical Investigation 1997100 1634-1639. (https://doi.org/10.1172/ JCI119687)

37 Grob F, Deladoey J, Legault L, Spigelblatt L, Fournier A, Vassart G $\&$ Van Vliet G. Autonomous adenomas caused by somatic mutations of the thyroid-stimulating hormone receptor in children. Hormone Research in Paediatrics 201481 73-79. (https://doi. org/10.1159/000357143)

Received 13 November 2020

Revised version received 21 December 2020

Accepted 15 January 2021 